\title{
Management of Glaucoma in Pregnancy
}

\section{Short Title: Glaucoma in pregnancy reviewed}

Sunu Mathew, MBBS, DNB ${ }^{1}$, Alon Harris, MS, PhD, FARVO ${ }^{1}$, Colin M Ridenour, $\mathrm{MD}^{1}$, Barbara M Wirostko, MD, $\mathrm{PhD}^{2}$, Kendall M Burgett, BS ${ }^{1}$, Molly D Scripture $\mathrm{BS}^{1}$, Brent Siesky, MS, $\mathrm{PhD}^{1}$

${ }^{1}$ Eugene and Marilyn Glick Eye Institute, Department of Ophthalmology, Indiana University School of Medicine, Indianapolis, IN, USA

${ }^{2}$ Moran Eye Center, Salt Lake City, UT, USA

Corresponding author:

Alon Harris, MS, PhD, FARVO

Lois Letzter Professor of Ophthalmology

Professor of Cellular and Integrative Physiology Department of Ophthalmology

Eugene and Marilyn Glick Eye Institute Indiana University School of Medicine

1160 West Michigan Street

Indianapolis, IN 46202

Phone: (317) 278-0177, Fax: (317) 278-1007

Email: alharris@indiana.edu

Pre'cis

Management of glaucoma in pregnancy is challenging. The optimal treatment option needs to provide adequate control of IOP for the mother while maintaining minimal risk for the fetus.

This is the author's manuscript of the article published in final edited form as:

Mathew, S., Harris, A., Ridenour, C. M., Wirostko, B. M., Burgett, K. M., Scripture, M. D., \& Siesky, B. (2019). Management of Glaucoma in Pregnancy. Journal of Glaucoma, Publish Ahead of Print. https://doi.org/10.1097/IJG.0000000000001324 


\section{Abstract}

Management of glaucoma during pregnancy represents a challenge for the physician. Important disease and patient health decisions begin even prior to conception and continue throughout pregnancy and breastfeeding. Data on this topic is limited due to ethical and legal constraints and challenges of conducting large, prospective, and randomized clinical trials on this patient population. Our review suggests that individually, intraocular pressure is lower in a pregnant woman when compared to a nonpregnant woman. Importantly, the medical management of glaucoma during pregnancy poses special challenges due to the possibility of adverse effects of medications on the fetus and newborn. Laser trabeculoplasty and traditional filtration surgery, as well as minimally invasive glaucoma surgery, represent non-drug management options. Thus, managing glaucoma in pregnancy is a delicate balance between treatment to prevent damage to the optic nerve in the mother and avoidance of interventions potentially harmful to the fetus. This literature review of published individual and population-based studies was performed in order to explore current knowledge and guidelines in the management of glaucoma in pregnancy.

Keywords: glaucoma, pregnancy, lactation, intraocular pressure, anti-glaucoma medications 


\section{Epidemiology}

Managing chronic diseases in pregnant women poses a unique challenge for physicians; the risks of limiting treatment options for the mother and the risk of exposing the fetus to disease management interventions. In addition, there is the added risk due to alterations in the physiology and hemodynamic state of the pregnant woman. Dueling paradigms of treatment and safety need to be carefully evaluated and glaucoma is no exception to this challenge. ${ }^{1}$ Importantly ophthalmologists often have limited confidence in addressing this subject. Vaideanu et al. conducted a survey of all consultant ophthalmologists in the United Kingdom, and their results indicated that many ophthalmologists are uncertain about the optimal strategy in the management of glaucoma in pregnancy. ${ }^{2}$ Due to the ethical and legal constraints of conducting large, prospective, and randomized clinical trials on this patient population, the data on this subject is limited. ${ }^{3}$ Without rigorous clinical research, physicians must rely on alternative forms of research and scientific literature to guide them in their decision making processes. There are case reports which describe women with glaucoma whose intraocular pressure (IOP) was difficult to control during pregnancy, despite medical and surgical intervention. Therefore it is important for physicians to be careful and knowledgeable while treating this patient population. ${ }^{4,5}$ Glaucoma has traditionally been considered a disease of old age, a survey of 3,494 patients under 40 who were examined in an urban optometric center showed that $0.4 \%$ of the sample had glaucoma and an additional $0.2 \%$ had suspected glaucoma. ${ }^{6}$ Thus although the prevalence is not very high in women of childbearing age, the decision to have children can significantly impact glaucoma management strategies.

This review explores the medical management of glaucoma in pregnancy and examines the various antiglaucoma drugs and their safety and efficacy during pregnancy and lactation. Articles from Pubmed published from1952-2017 were identified by using the keywords, glaucoma, pregnancy, lactation, intraocular pressure, and antiglaucoma medications.

\section{Preconception planning}

Women of childbearing age may have a history of glaucoma and already be on a treatment regimen. The situation is more complicated if pregnancy is unplanned since the greatest risk of treatment induced adverse effects to the fetus is in the first trimester of pregnancy: during organogenesis. ${ }^{7}$ Preconception counseling is the best recommended strategy in women of childbearing age with glaucoma. This helps women to understand potential benefits and risks of various treatment modalities, promotes better cooperation in evaluating IOP levels and fluctuations at more frequent intervals, as well as evaluating optic nerve and visual field function in order to assess the baseline status. It also helps to determine the risk of observation when treatment is discontinued, or fewer medications are entertained during pregnancy. If the glaucoma is uncontrolled, laser treatment or surgical intervention may be undertaken prior to conception to avoid side-effects of glaucoma medications during pregnancy.

\section{The eye in pregnancy}

Multiple studies have demonstrated that IOP in pregnant females is on average lower than non-pregnant females. ${ }^{8}$ Initial theories focused on the hormonal levels that fluctuate during pregnancy, such as estrogen, relaxin, progesterone, and $\beta$-human chorionic gonadotrophin. ${ }^{9-10}$ Later it was shown that the aqueous humor formation rate does not change during pregnancy, but that outflow facility increases during pregnancy, causing a 
decrease in IOP.$^{10}$ Ebeigbe et al, have shown that with advancing pregnancy, IOP decreases from $14.7 \mathrm{mmHg}$ in the first trimester to $11.0 \mathrm{mmHg}$ in the third trimester. ${ }^{11} \mathrm{In}$ addition, lower IOP has been associated with less severe fluctuations in IOP over the course of the day during the third trimester. ${ }^{12}$ The ocular hypotensive effects of pregnancy also extend to patients with preexisting ocular hypertension, although the time course differed between patient groups. Qureshi et al. found that, in normotensives, the significant decrease in IOP occurred in the $18^{\text {th }}$ week, while the decrease occurred later in the course of pregnancy in ocular hypertensive patients. In ocular hypertensive subjects, pregnancy may even bring the IOP down to within normal limits. ${ }^{13}$ Systemic hypertension has been shown to influence IOP in non-pregnant patients; however, the evidence in the pregnant population is mixed. Some studies found no significant difference in IOP in the third trimester between hypertensive and normotensive pregnant women ${ }^{14}$, while others found that the IOP in pregnant hypertensives was higher than the non-hypertensive pregnant women in the third trimester. ${ }^{15}$ It was also found that the decrease in IOP was independent of systemic BP, body weight and height. ${ }^{9}$ Evidence has also shown that multigravida have lower IOP than primigravidae, who in turn have lower IOP than non-pregnant women, although the exact mechanism of this difference is largely unknown. ${ }^{16}$ Despite our understanding of IOP changes that occur in non-glaucomatous pregnant females, we have limited data in pregnant patients with glaucoma. Brauner et al. followed 15 pregnant women with glaucoma throughout pregnancy and their individual disease course was mixed. In over half $(57.1 \%)$ of the eyes, IOP remained stable and there was no progression in the visual field. In $17.9 \%$ of eyes, there was visual field progression with stable or increased IOP. In $17.9 \%$ of eyes remained stable despite increasing IOP and the remaining eyes $(7.1 \%)$ were non-compliant to medications. ${ }^{17}$ While the natural course of IOP in healthy people decreases throughout pregnancy, the course of glaucoma during pregnancy is variable, and women must be monitored closely during pregnancy. Thus, managing IOP in pregnant women remains a challenge which is necessary to prevent pregnancy related vision loss. Some studies claimed that hormonal changes during pregnancy do not affect corneal biomechanics, ${ }^{18}$ while several other studies found that pregnancy was associated with increase corneal curvature, corneal volume, corneal innervation, and corneal thickness. ${ }^{19-}$ 22 This may be because of the various hormones on the cornea during pregnancy. Pregnancy is known to worsen diabetic retinopathy, as well as retinal detachments, central serous chorioretinopathy, and retinal vascular occlusive diseases. Retinal blood vessels have classically been examined as a way to monitor pre-eclampsia and eclampsia. ${ }^{23-26}$ The choroid is a highly vascularized tissue characterized by the highest blood flow to tissue volume ratio in the whole body. This makes it especially susceptible to hemodynamic and hormonal changes taking place in pregnancy, which may affect its thickness. ${ }^{27}$ Choroidal thickness has been found to be increased in pregnant versus nonpregnant women, ${ }^{28-31}$ and this thickening was maximum in the second trimester of pregnancy. ${ }^{32}$ The circulating blood volume increases from week 5-6 of pregnancy, and most rapidly from weeks 20 to 24 . As a result of the effect on the hemodynamics of the cardiovascular system in pregnancy, a decrease in vascular resistance prevails over the effect of an increase in blood volume; and thus results in a decrease in systolic and diastolic pressure. ${ }^{33}$ Laser Speckle Flowgraphy (LSFG) parameters have shown a 
decrease in resistance in the retinal blood vessels in normal pregnancy. Flow acceleration index (FAI) and resistive index (RI) values showed a significant decrease in the 3rd trimester, while blowout score (BOS) increased in the $3^{\text {rd }}$ trimester and mean blur rate (MBR) showed no significant changes throughout pregnancy. In addition, mean arterial pressure (MAP) was negatively correlated with FAI and RI while positively correlated with BOS. Thus, retinal vasculature provides a highly sensitive reflection of physiological changes in vascular resistance due to pregnancy. ${ }^{34,35}$

\section{Labor in Glaucomatous Patients}

Some studies have postulated that IOP during labor can vary depending on the stage of labor. ${ }^{36}$ Sixty-four (64) non-glaucomatous patients were evaluated during each stage of labor. This study found that mean IOP increased by $1.4 \mathrm{~mm} \mathrm{Hg}$ during the course of labor which was found to be statistically significant, and then decreased by $3.0 \mathrm{~mm} \mathrm{Hg}$ immediately after delivery. The IOP returned to pre-labor levels in all patients by 72 hours after delivery. It was postulated that an increase in oxytocin levels during labor leads to capillary constriction and a decrease in aqueous outflow. ${ }^{36}$ More recent studies performed on patients who received epidural anesthesia showed a mild increase in IOP and mean ocular perfusion pressure during the second stage, but this was not statistically significant. ${ }^{37}$ There is no evidence in the literature linking oxytocin with a rise in IOP. ${ }^{37}$ Whether this has any effect on the progression of glaucoma has not been studied, as the effects of a small change in IOP for a short period of time, on glaucomatous progression is unknown.. ${ }^{38}$ While not a part of the natural disease process, loss of large amounts of blood during labor may potentially lead to transient hypotension and ischemia, with an increased risk for optic nerve damage. ${ }^{39}$

\section{Medical Management of Glaucoma}

The pregnant (or planning to be pregnant) glaucoma patient presents a unique clinical challenge for ophthalmologists. The clinician is faced with balancing the risk of glaucomatous disease progression in the mother against the potential risks of interventions to the fetus or newborn child. The course of glaucoma in pregnancy may be complex. While numerous studies have supported the ocular hypotensive effects of pregnancy, including Qureshi et al. who found that patients with ocular hypertension also have reduced IOP in pregnancy, ${ }^{15}$ the IOP data in pregnant glaucoma patients remains undefined. In light of the limited and mixed results, it is important to evaluate each patient based on their individual glaucoma risk, need for treatment, and regular monitoring throughout pregnancy. Medical treatment of glaucoma carries a potential health risk to the developing fetus. Because of this potential risk, it is important to reduce the systemic absorption of topical glaucoma medications. Systemic absorption may be reduced by nasolacrimal occlusion (NLO), punctual plugging, or eyelid closure. Zimmerman et al. found that NLO or eyelid closure for 5 minutes reduced systemic absorption over $60 \%$. Both NLO and eyelid closure are safe, simple and effective ways to minimize dosage as well as side effects. ${ }^{40}$

When evaluating the individual risk of medications, it is useful to review the FDA Pregnancy Categories of various glaucoma medications (Table 1). While we do not have randomized clinical trials in pregnant glaucoma patients, animal studies and case reports can aid ophthalmologists when making treatment decisions and choosing pharmacologic therapies. The FDA Pregnancy Categories for medications include classes A, B, C, D and $\mathrm{X},{ }^{41}$ with glaucoma medications occupying classes $\mathrm{B}$ and $\mathrm{C}{ }^{3}$ To qualify as a Category A 
medicine there must be human studies that have failed to demonstrate risk to the fetus. There are currently no randomized prospective human studies for glaucoma medications in pregnancy. Furthermore, they are unlikely to be performed in the future due to ethical conflicts. Category B medicines include those where animal studies fail to demonstrate a risk to the fetus, but there are not adequate studies in pregnant women to elevate to Category $\mathrm{A}$. The Category $\mathrm{C}$ medications demonstrate adverse effects in animal fetuses, but again no adequate studies have been performed in humans. Category $\mathrm{C}$ medications may still benefit pregnant women despite the negative effects seen in animal models. Category D medications carry known human risk based on a history of adverse reactions, although their use may be warranted in some cases. Finally, Category X medications have shown fetal abnormalities in either humans or animals. The risks clearly outweigh the potential benefits from use of category X medications. ${ }^{41}$

The most common preservative in anti-glaucoma drugs is benzalkonium chloride (BAK). Animal studies on rats have shown a dose-related increase in fetal resorption and death, as well as a reduction in litter size and weight. Minor defects in the sternum were seen in fetuses exposed to a single dose of 100 and $200 \mathrm{mg} / \mathrm{kg}^{43}$ The concentration of BAK in anti-glaucoma eye drops varies from $0.005 \%$ to $0.2 \%,{ }^{44}$ In this dose, it can disrupt the lipid layer of the tear film and also cause evaporation of tears. It has also been shown to have cellular toxicity on caliciform cells. Systemically it may even cause a delayed type of hypersensitivity reaction (Type-IV). ${ }^{44}$

Beta-blockers: Beta-blockers are one of the first line treatment options for glaucoma patients and are FDA pregnancy category $C{ }^{3}$ This class of medication is typically prescribed as a topical preparation, but the IOP lowering effects occur with the systemic preparations as well. The topical beta blockers that are commonly used include timolol maleate, timolol hemihydrate, betaxolol, carteolol, levobunolol, and metipranolol. All of these medications, except for betaxolol, are non-selective beta antagonists. The nonselective agents have both beta- 1 and beta- 2 antagonistic activity. ${ }^{45,46}$ Beta- 1 receptors are primarily located in cardiac tissue, and the effect of beta- 1 selective antagonists is a decrease in heart rate. Beta-2 receptors are primarily located on the arteries of skeletal muscle and bronchioles of the lungs, and beta- 2 selective antagonists activation lead to bronchoconstriction. Betaxolol is a beta-1 selective antagonist; therefore, it avoids some of the systemic effects of the non-selective agents, although for IOP reduction it is less efficacious than non-selective medications. Additionally, carteolol, a non-selective beta antagonist, has intrinsic sympathetic activity and therefore some of the antagonistic actions are reduced. ${ }^{47}$

The beta blockers decrease IOP by decreasing aqueous humor production via inhibition of cAMP in the ciliary epithelium. The IOP lowering effects have been found with both systemic and topical beta-blocker use. While some ophthalmologists may be hesitant to use this medication in pregnant women, obstetricians frequently use systemic beta blockers in pregnancy to control hypertension. Some of the hesitation stems from both theoretical and reported concerns for neurological, cardiopulmonary, and growth restriction complications in the newborn. ${ }^{48-50}$ The neurological concerns stem from the side effects of lethargy, confusion, and depression seen from beta-blocker use. Studies support that by switching from timolol to betaxolol, which is a selective antagonist, the CNS effects are reduced. ${ }^{51,52}$

Data on the use of antiglaucoma medications, in particular beta-blockers, has yielded 
conflicting conclusions. Ho et al. conducted a population-based study ( $\mathrm{n}=244)$ in order to examine the relationship between the incidence of having a low-birth-weight (LBW) infant and the use of antiglaucoma medications during pregnancy. They concluded that while there was no significant difference in the risk of having LBW infants between mothers prescribed beta-blockers and mothers in the comparison cohort, there was a significantly higher risk of having a LBW infant for mothers prescribed other topical antiglaucoma medications compared to the control group. ${ }^{53}$ Similarly, Brauner et al found no significant complications including LBW. ${ }^{17}$ Of particular note is that they instructed all pregnant women to use punctual occlusion after installation of eyedrops to decrease systemic absorption. On the other hand, Razeghinejad et al in a small study found a statistically significant reduction in birth weight in infants born to mothers on topical beta-blockers. ${ }^{54}$ However, it should be noted that their patients were on topical combination therapy. Beta-blockers are known to affect cardiac physiology with side effects of bradycardia and possible arrhythmia. A published case report by Wagenvoort et al described a fetus with bradycardia and arrhythmia when the mother was on topical timolol. These side effects improved following a reduction in the medication concentration $^{55}$ and other studies have shown no evidence of changes in heart rate. ${ }^{56}$ Furthermore, beta-blockers can be actively secreted into breast milk and cause potential adverse effects in breastfed infants. In one case study, the concentration of timolol in breast milk was determined to be six times that of the plasma following topical ophthalmic use $\mathrm{s}^{57}$ and another study found betaxolol to be three times more concentrated in breast milk than in the plasma. ${ }^{58}$

Sympathomimetics: These are the only topical antiglaucoma medications classified as category $\mathrm{B}^{3}$. Non-selective agonists and selective alpha agonists like clonidine and apraclonidine are not used frequently in the treatment of chronic glaucoma due to the side effects such as nausea, vomiting, palpitations, and difficulty in micturition which are associated with chronic use. ${ }^{59-61}$ Brimonidine is the only drug in this category which is used on a long-term basis. Animal studies on pregnant rats and rabbits have revealed no damage to the fetus at doses much higher than the dose used at therapeutic levels in humans. ${ }^{62}$ Although considered safe to use in pregnancy, brimonidine is thought to be secreted in breast milk and should be discontinued in the third trimester as it causes central nervous system depression, hypotension, and apnea in infants. ${ }^{63,64}$

Carbonic anhydrase inhibitors: Acetazolamide and methazolamide are oral carbonic anhydrase inhibitors (CAI) used for glaucoma management. These agents are category $\mathrm{C}$ for use during pregnancy. Acetazolamide at high doses has been shown to produce birth defects in animals. ${ }^{65,66}$ However clinical or experimental studies looking at the adverse effects of acetazolamide on pregnancy outcomes in humans have shown mixed results. ${ }^{52}$, ${ }^{67-69}$ One isolated incidence of limb anomalies has been found in literature, but other studies ${ }^{70,71}$ have not shown any limb anomalies following systemic use of Carbonic anhydrase inhibitors in pregnancy. So if the clinical situation warrants the use of systemic acetazolamide, then the drug could be administered with appropriate informed consent. Animal studies have shown decreased weight gain in the offspring of lactating rats who have been exposed to very high doses of topical CAI. ${ }^{72,73}$ However, recent reports have shown mixed results in humans. It was earlier thought to be safe to use in humans ${ }^{17}$ but recently, there are a few reports of low birth weight ${ }^{53}$ and defects in renal tubular function in the newborn following maternal use of topical CAI. ${ }^{74}$ Although low plasma levels of 
acetazolamide have been reported in infants exposed to the medication through breast milk, ${ }^{75}$ the American Academy of Pediatricians has approved the use of CAIs during lactation, provided there is close monitoring of oral formulations. ${ }^{3}$

Prostaglandin analogs: Bimatoprost, latanoprost, travoprost, and tafluprost are prostaglandin-F2 analogs used as topical eye drops in patients with glaucoma. They belong to category $\mathrm{C}$ for use during pregnancy. ${ }^{3}$ Prostaglandins are also used systemically to induce labor by stimulating smooth muscle contraction. The contractile function has been demonstrated specifically of latanoprost, travoprost, and bimatoprost in non-pregnant uterus which had been isolated in rat models. ${ }^{76}$ Fortunately, there are no reports of premature labor in humans associated with the use of these drugs topically for glaucoma. There is no data available on the effect of tafluprost eye drops on the uterus. It has been shown that prostaglandin analogs are excreted in the breast milk of animals, although it is not known if they are excreted in the breast milk of humans. Whether or not topically administered medications reach plasma concentrations that could induce adverse effect on the pregnancy or on the fetus remains controversial. ${ }^{77}$ Although birth defects have been reported following the prenatal use of systemic prostaglandins, ${ }^{78}$ a small study by De Santis et al on 11 pregnant women showed that topical latanoprost exposure caused no adverse effects on either the pregnancy or the newborn. ${ }^{79}$ The difference in adverse events in this study compared to animal studies may be due to dosage levels. While De Santis's study found no evidence for adverse outcomes, the study was small and involved a 46-year-old female with miscarriage; however, this may be due to her advanced age. Being prodrugs, latanoprost and travoprost have the advantage of being converted into the active form once they pass the cornea with increased intraocular penetration and decreased local and systemic side effects, ${ }^{61}$, however, use in the case of severe glaucoma uncontrolled with other topical medication has not been prospectively studied. Latanoprostene is another prostaglandin-F2 analog which has entered the market. ${ }^{80}$

A new class of drug which has entered the market is Netarsudil which is an inhibitor of Rho kinase and norepinephrine transporter. ${ }^{81}$ It increases outflow of aqueous humor and decreases episcleral venous pressure. However, there are no studies which have looked into its safety during pregnancy and lactation.

Parasympathomimetics, Parasympathomimetics or cholinergic agents, are classified as category $\mathrm{C}$ drugs. Although pilocarpine and carbachol injected into the yolk sac have demonstrated teratogenic and adverse fetal effects in animals ${ }^{82}$ Kooner et al. found no association between congenital abnormalities and the use of topical cholinergic agents during the first 4 months of gestation. ${ }^{60}$ Cholinergic receptors are found on the placenta, and it is thought that they are linked to myometrial and placental prostaglandin release and regulation of placental perfusion. ${ }^{83}$ There are reports of hyperthermia, seizures, or restlessness in neonates and therefore these medications are generally avoided in the postpartum period. ${ }^{84}$ Due to the availability of safer and more effective drugs with other classes of antiglaucoma medications, parasympathomimetics are not used in management of glaucoma in pregnancy. (Table 2)

\section{Laser filtration procedure in Glaucoma}

When medical treatment fails or is not an option to control IOP or there is progression of visual field damage in a pregnant female with glaucoma, laser filtration options need to

be considered. ${ }^{85}$ Laser procedures are useful to reduce or eliminate the use of medications 
which may be potentially harmful to the fetus. When considering laser procedures, special consideration must be given to the angle of the anterior chamber. Glaucoma in this age group could be secondary to congenital conditions like Axenfeld-Reiger's syndrome, Sturge Weber syndrome, Peter's anomaly or aniridia. ${ }^{86}$ It may also be secondary to inflammatory conditions like uveitis or trauma. These may prove to be challenging in terms of management.

Laser procedures offer the least risk to the unborn fetus. Advantages over incisional surgery are that it requires only topical anesthesia, can be performed in an upright position, is an outpatient procedure with very little pre- and post-operative medication requirement, and patients demonstrate faster rehabilitation, all of which are of advantage both in early and advanced stages of pregnancy. ${ }^{87}$ The most frequently done procedure is neodymium: yttrium-aluminum-garnet (Nd:YAG) laser peripheral iridotomy for narrowangle glaucoma. ${ }^{88}$ Another procedure performed on the iris is the laser peripheral iridoplasty in which laser burns are applied to the peripheral iris to facilitate widening of the anterior chamber angle or to lyse peripheral anterior synechiae. Argon laser trabeculoplasty in which evenly spaced burns are placed on the anterior trabecular meshwork for 180 or even 360 degrees of the angle. It causes both structural and coagulative damage to the tissues of the trabecular meshwork. ${ }^{89}$ Selective laser trabeculoplasty, on the other hand, is less disruptive to the tissues. The laser-induced thermal damage is confined to pigmented areas within an irradiated tissue. ${ }^{90}$ Using micropulse diode laser, the thermal spread of laser energy and consequent coagulative damage can be avoided. ${ }^{91}$ However, laser filtration procedures are not very effective in controlling IOP in patients younger than 50 years of age. ${ }^{92}$

\section{Surgery in Glaucoma}

Surgical options include traditional filtration surgery and minimally invasive glaucoma surgery (MIGS). It should be noted that drugs used during surgical interventions and for postoperative care should be reviewed and considered as sources of risk.

There are several risks to be considered when planning invasive filtration surgery in a pregnant glaucomatous patient. These include the risks of local and systemic anesthetic medications and pre- and post-operative medications. ${ }^{94}$ Inhaled anesthetic agents and central nervous system depressants used to anesthetize the patient can be harmful to the fetus. This is particularly true of general anesthetic agents, which have been shown to cause an increased incidence of low birth weight and neural tube defects when administered to the mother in her first trimester. ${ }^{95}$ Most local anesthetics have not been shown to be teratogenic in humans and are considered relatively safe for use during pregnancy. Lidocaine and etidocaine are classified as group B and bupivacaine and mepivacaine are in group $\mathrm{C}$ because they have a tendency to induce fetal bradycardia. ${ }^{96}$ Retrobulbar anesthesia may produce more systemic absorption than subconjunctival and anterior sub-Tenon's anesthesia combined with topical anesthesia for glaucoma surgery. ${ }^{96}$ Position of the patient during surgery is important especially in second and third trimester of pregnancy. The gravid uterus may compress the aorta or inferior vena cava and cause severe hypotension. To prevent this, the patient will need to be rotated towards the left side at the level of hips or thighs while keeping the head steady. ${ }^{97}$

Failure rate following glaucoma filtration surgery is high due to the young age of the patient and physiological changes that occur naturally in pregnancy. Levels of vascular endothelial growth factor (VEGF) and placental growth factor (PGF) are elevated in 
pregnancy and aid in cell migration of fibroblasts and inflammatory cells and promote proliferation favoring wound healing. ${ }^{98}$ However, the antimetabolites, which are commonly used following filtration surgery, such as Mitomycin $\mathrm{C}$ and 5 Fluorouracil are FDA category $\mathrm{X}$ teratogens and therefore are absolutely contraindicated in pregnancy. ${ }^{99}$,

${ }^{100}$ Filtration surgery without the use of antimetabolites, favors fibrosis of the incision site leading to increased chance of failure. An alternative would be MIGS and or aqueous shunt surgery for patients who need surgery in pregnancy. ${ }^{101}$ The Tube versus Trabeculectomy study has helped to highlight shunt surgery as an alternative to conventional filtration surgery. ${ }^{102}$ Over the last few years, advances in glaucoma surgery have expanded the surgical options available for a pregnant woman with glaucoma, requiring surgery. In MIGS, the ab interno approach prevents damage to the conjunctiva and helps to reduce the number of postoperative medications required. ${ }^{103}$ It may also probably be safer compared to traditional filtration procedures. In addition, several micro stents are now available which help to increase aqueous outflow with less disturbance to the ocular structures.

\section{Management Plan}

Pre-conception counseling: Women in the childbearing age who have a history of glaucoma may already be on anti-glaucoma medications. If the pregnancy is unplanned, it can pose a risk to the fetus since the first trimester is the period of organogenesis and this may be adversely affected by the medication ${ }^{7}$. Hence preconception planning is ideal in women of childbearing age who have glaucoma. Counseling helps the woman understand the potential benefits and risks of various treatment modalities. This will help pave the way for better patient communication and cooperation, including more frequent evaluations of IOP levels, visual field examinations, and optic nerve evaluations, after the baseline evaluations. This, in turn, will help determine the course of management of glaucoma during pregnancy. If the glaucoma is well controlled the woman may be taken off the medication and observed during the course of her pregnancy or the number and frequency of medication may be reduced. In uncontrolled cases, the preconception stage is ideal for any intervention either laser trabeculoplasty or surgical intervention as the risk to the fetus is nil at this stage.

First trimester: By the time the pregnancy is identified, organogenesis would have already started to occur. If pressures can be kept under control without treatment, close monitoring of IOP and visual fields would be the ideal option. Consideration of medications used during first trimester is crucial. Brimonidine, a category B drug, is the safest option and beta-blockers, although a category $\mathrm{C}$ drug, can also be used as a first line drug. Surgery may be best avoided in the first trimester.

Second trimester: Beta-blockers and brimonidine can be used with close monitoring of the fetal heart rate and fetal growth during this period. Patient should be educated to watch for symptoms of premature labor if topical prostaglandin analogs are used. Third trimester: Beta-blockers and CAIs are the ideal medications to be used in this period if IOP lowering is needed. Brimonidine should be stopped late in the third trimester to avoid central nervous system depression in newborn.

Lactation: Both beta-blockers and CAIs can be used during lactation, although betablockers are best avoided if the baby has preexisting cardiac problems. Concerning prostaglandins, because of its short half-life, it is unlikely to cause any harm in breastfed infants 
Laser treatment options including trabeculoplasty can be considered if IOP is uncontrolled with medications. Trabeculoplasty: Argon laser, selective laser or micropulse diode laser trabeculoplasty can be performed for better control of IOP. Surgery: Filtration surgery can be performed with caution in second and third trimester if IOP is not controlled by medications and laser trabeculoplasty.

\section{Conclusion}

Managing glaucoma in pregnancy is a delicate balance between control of IOP to prevent damage to the optic nerve in the mother and avoidance of interventions that are potentially harmful to the fetus. Optimum treatment strategies for glaucoma in pregnancy should begin prior to conception and include careful consideration of risks to both the mother and fetus. Preservation of the optic nerve and vision in the mother are predominate considerations, however, considerations of risk to the unborn child must be carefully considered and discussed with the glaucoma patient. Newer and less invasive surgical interventions such as MIGS may be novel options, however, postoperative medications still need to be considered during the management of glaucoma in pregnancy. An open dialog and close relationship between clinician and females of child-bearing age about the risks and options of pregnancy in glaucoma is vital to producing best possible outcomes for all involved.

Financial disclosures and Conflict of interest.

There are no conflicts of interest.

Dr. Alon Harris would like to disclose that he receives remuneration from Shire, CIPLA and AdOM for serving as a consultant. Dr. Harris also holds an ownership interest in AdOM and Oxymap.

All relationships listed above are pursuant to Indiana University's policy on outside activities. 


\section{References}

1. Denis D, Touvron G. Glaucoma management during pregnancy. J Fr Ophtalmol 2010; 33: 346-349.

2. Vaideanu D, Fraser S. Glaucoma management in pregnancy: a questionnaire survey. Eye (Lond) 2007; 21: 341-343.

3. Salim S. Glaucoma in pregnancy. Curr Opin Ophthalmol 2014; 25: 93-97.

4. Wertheim M, Broadway DC. Cyclodiode laser therapy to control intraocular pressure during pregnancy. Br J Ophthalmol 2002; 86: 1318-1319.

5. Johnson SM, Maritnez M, Freedman S. Management of glaucoma in pregnancy and lactation. Surv Ophthalmol 2001; 45: 449-454.

6. Werner DL, Sherman J. Prevalence of glaucoma in optometric patients under 40 years of age. Am J Optom Physiol Opt 1977; 54: 767-770.

7. Zeyen $\mathrm{T}$ and Coppens G. Medical treatment: the pregnant and nursing woman. In: Giaconi JA, Law SK, Coleman AL, Caprioli J (eds) Pearls of glaucoma management. Berlin: Springer; 2010: 203-205.

8. Wang C, Li AL, Pang Y, et al. Changes in intraocular pressure and central corneal thickness during pregnancy: a systematic review and Meta-analysis. Int $J$ Ophthalmol. 2017; 18:10(10):1573-1579.

9. Posthumus RG. The use and the possibilities of progesterone in the treatment of glaucoma. Ophthalmologica 1952; 124: 17-25.

10. Ziai N, Ory SJ, Khan AR, et al. $\beta$-human chorionic gonadotropin, progesterone, and aqueous dynamics during pregnancy. Arch Ophthalmol 1994; 112: 801-806. 
11. Ebeigbe JA, Ebeigbe PN, Ighoroje AD. Intraocular pressure in pregnant and nonpregnant Nigerian women. Afr J Reprod Health. 2011 Dec; 15(4):20-3.

12. Qureshi IA, Xi XR, Wu XD, et al. Effect of third trimester of pregnancy on diurnal variation of ocular pressure. Chin Med Sci J 1997; 12: 240-243.

13. Qureshi IA. Intraocular pressure and pregnancy: a comparison between normal and ocular hypertensive subjects. Arch Med Res 1997; 28: 397-400.

14. Phillips CI, Gore SM. Ocular hypotensive effect of late pregnancy with and without high blood pressure. Br J Ophthalmol 1985; 69: 117-119.

15. Qureshi IA, Xi XR, Wu XD. Intraocular pressure trends in pregnancy and in the third trimester hypertensive patients. Acta Obstet Gynecol Scand 1996; 75: 816819.

16. Qureshi IA, Xi XR, Yaqob T. The ocular hypotensive effect of late pregnancy is higher in multigravidae than in primigrayidae. Graefes Arch Clin Exp Ophthalmol 2000; 238: 64-67.

17. Brauner SC, Chen TC, Hutchinson BT, et al. The course of glaucoma during pregnancy: a retrospective case series. Arch Ophthalmol 2006; 124: 1089-1094.

18. Sen E, Onaran Y, Nalcacioglu-Yuksekkaya P, et al. Corneal biomechanical parameters during pregnancy. Eur J Ophthalmol 2014; 24: 314-319.

19. Goldich Y, Cooper M, Barkana Y, et al. Ocular anterior segment changes in pregnancy. J Cataract Refract Surg 2014; 40: 1868-1871.

20. Efe YK, Ugurbas SC, Alpay A, et al. The course of corneal and intraocular pressure changes during pregnancy. Can J Ophthalmol 2012; 47: 150-154.

Copyright (C) 2019 Wolters Kluwer Health, Inc. Unauthorized reproduction of the article is prohibited. 
21. Ataş M, Duru N, Ulusoy DM, et al. Evaluation of anterior segment parameters during and after pregnancy. Cont Lens Anterior Eye 2014; 37: 447-450.

22. Gotovac M, Kastelan S, Lukenda A. Eye and pregnancy. Coll Antropol 2013; 37: 189-193.

23. Omoti AE, Waziri-Erameh JM, Okeigbemen VW. A review of the changes in the ophthalmic and visual system in pregnancy. Afr J Reprod Health 2008; 12: 185196.

24. Lupton SJ, Chiu CL, Hodgson LA, et al. Changes in retinal microvascular caliber precede the clinical onset of preeclampsia. Hypertension 2013; 62: 899-904.

25. Garg A, Wapner RJ, Ananth CV, et al. Choroidal and retinal thickening in severe preeclampsia. Invest Ophthalmol Vis Sci 2014; 55: 5723-5729.

26. Errera MH, Kohly RP, da Cruz L. Pregnancy-associated retinal diseases and their management. Surv Ophthalmol 2013; 58: 127-142.

27. Nickla DL, Wallman J. The multifunctional choroid. Prog Retin Eye Res 2010; 29: 144-168.

28. Liu R, Kuang GP, Luo DX, et al. Choroidal thickness in pregnant women: a crosssectional study. Int J Ophthalmol 2016; 9: 1200-1206.

29. Roskal-Wałek J, Laudańska-Olszewska I, Biskup M, et al. Choroidal Thickness in Women with Uncomplicated Pregnancy: Literature Review. Biomed Res Int 2017; 2017: 1-8.

30. Kara N, Sayin N, Pirhan D, et al. Evaluation of subfoveal choroidal thickness in pregnant women using enhanced depth imaging optical coherence tomography. Curr Eye Res 2014; 39: 642-647. 
31. Ulusoy DM, Duru N, Ataş M, et al. Measurement of choroidal thickness and macular thickness during and after pregnancy. Int J Ophthalmol 2015; 8: 321-325.

32. Goktas S, Basaran A, Sakarya Y, et al. Measurement of choroid thickness in pregnant women using enhanced depth imaging optical coherence tomography. Arq Bras Oftalmol 2014; 77: 148-151.

33. Ouzounian JG, Elkayam U. Physiologic changes during normal pregnancy and delivery. Cardiol Clin 2012; 30: 317-329.

34. Sato T, Sugawara J, Aizawa N, et al. Longitudinal changes of ocular blood flow using laser speckle flowgraphy during normal pregnancy. PLoS One 2017; 12:e0173127.

35. Kiyota N, Kunikata H, Shiga Y, Omodaka K, Nakazawa T. Relationship between laser speckle flowgraphy and optical coherence tomography angiography measurements of ocular microcirculation. Graefes Arch Clin Exp Ophthalmol. 2017 Aug;255(8):1633-1642.

36. Avasthi P, Sethi P, Mithal S. Effect of pregnancy and labor on intraocular pressure. Int Surg 1976; 61: 82-84.

37. Meshi A, Armarnik S, Mimouni M, et al. The Effect of Labor on the Intraocular Pressure in Healthy Women. J Glaucoma 2017; 26: 59-64.

38. Bito L Z. Glaucoma: A Physiologic Perspective with Darwinian Overtones. J Glaucoma 1992; 1: 193-205.

39. Costa VP, Arcieri ES, Harris A. Blood pressure and glaucoma. Br J Ophthalmol 2009; 93: 1276-1282.

Copyright (C) 2019 Wolters Kluwer Health, Inc. Unauthorized reproduction of the article is prohibited. 
40. Zimmerman TJ, Kooner KS, Kandarakis AS, et al. Improving the therapeutic index of topically applied ocular drugs. Arch Ophthalmol 1984; 102: 551-553.

41. Law R, Bozzo P, Koren G, et al. FDA pregnancy risk categories and the CPS: do they help or are they a hindrance? Can Fam Physician 2010; 56: 239-241.

42. Terminology and Guidelines for Glaucoma, 4th ed. Savona, Italy: European Glaucoma Society, 2014.

43. Buttar HS. Embryotoxicity of benzalkonium chloride in vaginally treated rats. $J$ Appl Toxicol 1985; 5: 398-401.

44. Coroi MC, Bungau S, and Tit M. Preservatives from the eye drops and the ocular surface. Rom J Ophthalmol. 2015 Jan-Mar; 59(1): 2-5.

45. Schlote T. Mode of action, clinical profile and significance of beta-blockers in antiglaucoma therapy. Klin Monbl Augenheilkd 2013; 230: 120-126.

46. Özcan KS, Güngör B, Osmonov D, et al. Management and outcome of topical betablocker-induced atrioventricular block. Cardiovasc J Afr 2015; 26: 210-213.

47. Taniguchi T, Kitazawa Y. The potential systemic effect of topically applied betablockers in glaucoma therapy. Curr Opin Ophthalmol 1997; 8: 55-58.

48. Xie RH, Guo Y, Krewski D, et al. Trends in using beta-blockers and methyldopa for hypertensive disorders during pregnancy in a Canadian population. Eur J Obstet Gynecol Reprod Biol 2013; 171: 281-285.

49. Ersbøll AS, Hedegaard M, Søndergaard L, et al. Treatment with oral beta-blockers during pregnancy complicated by maternal heart disease increases the risk of fetal growth restriction. BJOG 2014; 121: 618-626.

Copyright (C) 2019 Wolters Kluwer Health, Inc. Unauthorized reproduction of the article is prohibited. 
50. Xie RH, Guo Y, Krewski D, et al. Beta-blockers increase the risk of being born small for gestational age or of being institutionalised during infancy. BJOG 2014; 121: 1090-1096.

51. Lynch MG, Whitson JT, Brown RH, et al. Topical beta-blocker therapy and central nervous system side effects. A preliminary study comparing betaxolol and timolol. Arch Ophthalmol 1988; 106: 908-911.

52. Duch S, Duch C, Pastó L, et al. Changes in depressive status associated with topical beta-blockers. Int Ophthalmol 1992; 16: 331-335.

53. Ho JD, Hu CC, Lin HC. Antiglaucoma medications during pregnancy and the risk of low birth weight: a population-based study. Br J Ophthalmol 2009; 93:12831286.

54. Razeghinejad MR, Nowroozzadeh MH. Anti-glaucoma medication exposure in pregnancy: an observational study and literature review. Clin Exp Optom 2010; 93: $458-465$.

55. Wagenvoort AM, Van vugt JM, Sobotka M, et al. Topical timolol therapy in pregnancy: is it safe for the fetus? Teratology 1998; 58: 258-262.

56. Pellegrino $\mathrm{M}^{1}$, D'Oria $\mathrm{L}^{1}$, De Luca $\mathrm{C}^{1}$, Chiaradia $\mathrm{G}^{2}$, Licameli $\mathrm{A}^{1}$, Neri $\mathrm{C}^{1}$, Nucci $\mathrm{M}^{1}$, Visconti $\mathrm{D}^{1}$, Caruso $\mathrm{A}^{1}$, De Santis $\mathrm{M}^{1}$. Glaucoma Drug Therapy in Pregnancy: Literature Review and Teratology Information Service (TIS) Case Series. Curr Drug Saf. 2018;13(1):3-11.

57. Lustgarten JS, Podos SM. Topical timolol and the nursing mother. Arch Ophthalmol 1983; 101: 1381-1382. 
58. Morselli PL, Boutroy MJ, Bianchetti G, et al. Placental transfer and perinatal pharmacokinetics of betaxolol. Eur J Clin Pharmacol 1990; 38: 477-483.

59. Kooner KS, Zimmerman TJ. Antiglaucoma therapy during pregnancy—Part II. Ann Ophthalmol 1988; 20: 208-211.

60. Netland P. Glaucoma Medical Therapy: Principles and Management, $2^{\text {nd }}$ ed. New York: Oxford University Press, 2008.

61. Keränen A, Nykänen S, Taskinen J. Pharmacokinetics and side-effects of clonidine. Eur J Clin Pharmacol 1978; 13: 97-101.

62. Allergan, Inc, Alphagan P product monograph. Irvine, California: Allergan, Inc, 2008.

63. Fudemberg SJ, Batiste C, Katz LJ. Efficacy, safety, and current applications of brimonidine. Expert Opin Drug Saf 2008; 7: 795-799.

64. Sethi HS, Naik M, and Gupta VS. Management of glaucoma in pregnancy: risks or choices, a dilemma? Int J Ophthalmol. 2016; 9(11): 1684-1690.

65. Kojima N, Naya M, Makita T. Effects of maternal acetazolamide treatment on body weights and incisor development of the fetal rat. J Vet Med Sci 1999; 61: 143-147.

66. Milaire J. Teratogenic effects of acetazolamide in mouse embryos. Bull Mem Acad R Med Belg 1991; 146: 231-238.

67. Ozawa H, Azuma E, Shindo K, et al. Transient renal tubular acidosis in a neonate following transplacental acetazolamide. Eur J Pediatr 2001; 160: 321-322.

68. Worsham F, Jr, Beckham EN, Mitchell EH. Sacrococcygeal teratoma in a neonate. Association with maternal use of acetazolamide. JAMA 1978; 240: 251-252. 
69. Lee AG, Pless M, Falardeau J, et al. The use of acetazolamide in idiopathic intracranial hypertension during pregnancy. Am J Ophthalmol 2005; 139: 855-859.

70. Afnan I Al-Saleem ${ }^{1}$ and Asma M Al-Jobair ${ }^{2}$ Possible association between acetazolamide administration during pregnancy and multiple congenital malformations. Drug Des Devel Ther. 2016; 10: 1471-1476.

71. Falardeau J, Lobb BM, Golden S, Maxfield SD, Tanne E. The Use of Acetazolamide During Pregnancy in Intracranial Hypertension Patients. Journal of Neuro-Ophthalmology. 2013 Mar; 33(1):9-12.

72. Alcon Ophthalmics, Azopt product monograph. Fort Worth, Texas: Alcon Ophthalmics, 1998.

73. Merck \& Co., Inc., Trusopt product monograph. West Point, Pennsylvania: Merck \& Co., Inc., 1999.

74. Morris S, Geh V, Nischal K, et al. Topical dorzolamide and metabolic acidosis in a neonate. Br J Ophthalmol 2003; 87: 1052-1053.

75. Soderman P, Hartvig P, Fagerlund C. Acetazolamide excretion into human breast milk. Br J Clin Pharmac 1984; 17: 599-600.

76. Sharif NA. Synthetic FP-prostaglandin-induced contraction of rat uterus smooth muscle in vitro. Prostaglandins Leukot Essent Fatty Acids 2008; 78: 199-207.

77. Barbazetto IA, Pizzarello LD. Ocular changes during pregnancy. Compr Ophthalmol Update 2007; 8: 155-167.

78. da Silva Dal Pizzol T, Knop FP, Mengue SS. Prenatal exposure to misoprostol and congenital anomalies: systematic review and meta-analysis. Reprod Toxicol 2006; 22: 666-671.

Copyright (C) 2019 Wolters Kluwer Health, Inc. Unauthorized reproduction of the article is prohibited. 
79. De Santis M, Lucchese A, Carducci B, et al. Latanoprost exposure in pregnancy. Am J Ophthalmol 2004; 138: 305-306.

80. Hoy SM. Latanoprostene Bunod Ophthalmic Solution 0.024\%: A Review in OpenAngle Glaucoma and Ocular Hypertension. Drugs. 2018 May;78(7):773-780.

81. Kazemi A, McLaren JW, Kopczynski CC, Heah TG, Novack GD, Sit AJ. The Effects of Netarsudil Ophthalmic Solution on Aqueous Humor Dynamics in a Randomized Study in Humans. J Ocul Pharmacol Ther. 2018 Jun;34(5):380-386

82. Walter L. The teratogenic activity of pilocarpine, pilocarpidine and their isomers, with special reference to the importance of steric configuration. J Exper Zool 1956; 132: $39-50$.

83. Rama Sastry BV, Olubadewo J, Harbison RD, et al. Human placental cholinergic system. Occurrence, distribution and variation with gestational age of acetylcholine in human placenta. Biochem Pharmacol 1976; 25: 425-431.

84. Samples JR, Meyer BS. Use of ophthalmic medications in pregnant and nursing women. Am J Ophthalmol 1988; 106: 616-623.

85. Razeghinejad MR, Tania Tai TY, Fudemberg SJ, et al. Pregnancy and glaucoma. Surv Ophthalmol 2011; 56: 324-335.

86. Emanuel M E, .Gedde S J. Indications for a systemic work-up in glaucoma Canadian Journal of Ophthalmology 2014; 49(6): 506-511

87. Geffen N, Assia EI, Melamed S. Laser-Assisted Techniques for Penetrating and Nonpenetrating Glaucoma Surgery. Dev Ophthalmol. 2017;59:100-112.

88. Kumar H, Mansoori T, Warjri GB, et al. Lasers in glaucoma. Indian J Ophthalmol. 2018 Nov;66(11):1539-1553.

Copyright (C) 2019 Wolters Kluwer Health, Inc. Unauthorized reproduction of the article is prohibited. 
89. The Glaucoma Laser Trial Research Group. The Glaucoma Laser Trial (GLT). 2: results of argon laser trabeculoplasty versus topical medicines. Ophthalmology 1990; 97: 1403-1413.

90. McIlraith I, Strasfeld M, Colev G,et al. Selective laser trabeculoplasty as initial and adjunctive treatment for open-angle glaucoma. J Glaucoma 2006; 15: 124-130.

91. Fudemberg SJ, Myers JS, Katz LJ . Trabecular Meshwork Tissue Examination With Scanning Electron Microscopy: A Comparison of Micropulse Diode Laser (MLT), Selective Laser (SLT), and Argon Laser (ALT) Trabeculoplasty in Human Cadaver Tissue. Investigative Ophthalmology \& Visual Science May 2008, Vol.49, 1236.

92. Safran MJ, Robin AL, Pollack IP. Argon laser trabeculoplasty in younger patients with primary open-angle glaucoma. Am J Ophthalmol 1984; 97: 292-295.

93. Razeghinejad MR, Masoumpour M, Eghbal MH, et al. Glaucoma Surgery in Pregnancy: A Case Series and Literature Review. Iran J Med Sci 2016; 41: 437445.

94. Cheek TG, Baird E. Anesthesia for nonobstetric surgery: maternal and fetal considerations. Clin Obstet Gynecol 2009; 52: 535-545.

95. Mazze RI, Kallen B. Reproductive outcome after anesthesia and operation during pregnancy: a registry study of 5405 cases. Am J Obstet Gynecol 1989; 161: 11781185.

96. Shammas HJ, Milkie M, Yeo R. Topical and subconjunctival anesthesia for phacoemulsification: prospective study. J Cataract Refract Surg 1997; 23: 1577 1580.

Copyright (C) 2019 Wolters Kluwer Health, Inc. Unauthorized reproduction of the article is prohibited. 
97. Kuczkowski KM. Nonobstetric surgery in the parturient: anesthetic considerations. J Clin Anesth. 2006;18:5-7.

98. Anthony FW, Evans PW, Wheeler T, et al, Variation in detection of VEGF in maternal serum by immunoassay and the possible influence of binding proteins. Ann Clin Biochem 1997; 34: 276-280.

99. Autiero M, Luttun A, Tjwa M, et al. Placental growth factor and its receptor, vascular endothelial growth factor receptor-1: novel targets for stimulation of ischemic tissue revascularization and inhibition of angiogenic and inflammatory disorders. J Thromb Haemost 2003; 1: 1356-1370.

100. Nilforushan N, Yadgari M, Kish SK, et al. Subconjunctival bevacizumab versus mitomycin C adjunctive to trabeculectomy. Am J Ophthalmol 2012; 153: 352-357.

101. Olali C, Rotchford AP, King AJ. Outcome of repeat trabeculectomies. Clin Experiment Ophthalmol 2011; 39: 658-664.

102. Gedde SJ, Schiffman JC, Feuer WJ, et al. Treatment outcomes in the Tube Versus Trabeculectomy (TVT) study after five years of follow-up. Am J Ophthalmol 2012; 153: 789-803.

103. Pillunat LE, Erb C, Jünemann AG, Micro-invasive glaucoma surgery (MIGS): a review of surgical procedures using stents. Clin Ophthalmol. 2017 Aug 29;11:15831600. 


\begin{tabular}{|l|l|}
\hline Class A & $\begin{array}{l}\text { Controlled studies show no risk. Adequate well-controlled studies in pregnant women have } \\
\text { not shown any risk to the fetus }\end{array}$ \\
\hline Class B & $\begin{array}{l}\text { No evidence of risk in humans. Either animal studies have shown risk, but human studies } \\
\text { have not or, if no adequate human studies have been done, animal studies are negative. }\end{array}$ \\
\hline Class C & $\begin{array}{l}\text { Risk cannot be ruled out. Human studies are lacking, and animal studies are either positive } \\
\text { for fetal risk or inadequate as well. However potential benefits may outweigh the potential } \\
\text { risk. }\end{array}$ \\
\hline Class D & $\begin{array}{l}\text { Definite evidence of risk. Investigational or post-marketing data show some risk to the } \\
\text { fetus. But, potential benefits may outweigh the potential risk. }\end{array}$ \\
\hline Class X & $\begin{array}{l}\text { Contraindicated in pregnancy. Studies in animals or human or investigational or post- } \\
\text { marketing reports have shown fetal risk which clearly outweighs any benefit to the patient. }\end{array}$ \\
\hline
\end{tabular}

Table 1: FDA Pregnancy Categories ${ }^{42}$ 


\begin{tabular}{|c|c|c|c|c|c|}
\hline & \multirow{3}{*}{ Class } & \multicolumn{3}{|l|}{ Pregnancy } & \multirow{3}{*}{ Breast-Feeding } \\
\hline & & \multirow[b]{2}{*}{ Animal Studies } & \multicolumn{2}{|l|}{ Humans } & \\
\hline & & & Theoretical Risk & $\begin{array}{l}\text { Documented } \\
\text { Cases }\end{array}$ & \\
\hline Beta Blockers & $\mathrm{C}$ & $\begin{array}{l}\text { Fetal resorption, } \\
\text { delayed fetal } \\
\text { ossification }\end{array}$ & $\begin{array}{l}\text { Teratogenicity (in } \\
1^{\text {st }} \text { trimester), } \\
\text { cardiac rhythm } \\
\text { changes, and } \\
\text { respiratory } \\
\text { changes }\end{array}$ & $\begin{array}{l}\text { Arrhythmia, } \\
\text { bradycardia, } \\
\text { and impaired } \\
\text { respiratory } \\
\text { control in } \\
\text { newborn }\end{array}$ & $\begin{array}{l}\text { Controversy over } \\
\text { drug } \\
\text { concentrations in } \\
\text { breast milk. Can } \\
\text { cause apnea and } \\
\text { bradycardia }\end{array}$ \\
\hline $\begin{array}{l}\text { Sympathomimetics } \\
\text { (i.e. brimonidine) }\end{array}$ & B & $\begin{array}{l}\text { No significant } \\
\text { effect }\end{array}$ & $\begin{array}{l}\text { Uterine hypotony } \\
\text { / delayed labor }\end{array}$ & $\begin{array}{l}\text { No reported } \\
\text { side-effects }\end{array}$ & $\begin{array}{l}\text { CNS depression, } \\
\text { hypotension, and } \\
\text { apnea }\end{array}$ \\
\hline \multicolumn{6}{|l|}{$\begin{array}{l}\text { Carbonic Anhydrase } \\
\text { Inhibitors }\end{array}$} \\
\hline Topical & $\mathrm{C}$ & $\begin{array}{l}\text { Decreased weight } \\
\text { gain and vertebral } \\
\text { body malformation }\end{array}$ & Low birth we & $\begin{array}{l}\text { No reported } \\
\text { side-effects }\end{array}$ & $\begin{array}{l}\text { No reported side- } \\
\text { effects }\end{array}$ \\
\hline Oral & $\mathrm{C}$ & Forelimb anomalies & $\begin{array}{l}\text { Limb } \\
\text { malformati }\end{array}$ & $\begin{array}{l}\text { One reported } \\
\text { case of } \\
\text { teratoma }\end{array}$ & $\begin{array}{l}\text { No reported side- } \\
\text { effects }\end{array}$ \\
\hline Prostaglandin Analogs & $\mathrm{C}$ & $\begin{array}{l}\text { High incidence of } \\
\text { miscarriage }\end{array}$ & $\begin{array}{l}\text { Uterine } \\
\text { contractions }\end{array}$ & $\begin{array}{l}\text { One reported } \\
\text { case of } \\
\text { miscarriage }\end{array}$ & $\begin{array}{l}\text { No reported side- } \\
\text { effects }\end{array}$ \\
\hline Parasympathomimetics & $\mathrm{C}$ & Teratogenic & $\begin{array}{l}\text { Teratogenicity } \\
\text { and dysregulation } \\
\text { of placental } \\
\text { perfusion }\end{array}$ & $\begin{array}{l}\text { Meningism in } \\
\text { the newborn }\end{array}$ & $\begin{array}{l}\text { Seizures, fever, } \\
\text { and diaphoresis }\end{array}$ \\
\hline
\end{tabular}

Table 2: Adverse Effects of Glaucoma Medications during Pregnancy and Breast-Feeding ${ }^{42}$ 